\title{
Low Cycle Fatigue of an Ultrafine Grained AA5083 Aluminum Alloy Composite Produced by Cryomilling
}

\author{
A. CONTRERAS, R.G. VOGT, D.M. OLIVEIRA, J.M. SCHOENUNG, \\ and J.C. GIBELING
}

Low cycle fatigue (LCF) properties were investigated for a novel cryomilled AA5083 aluminum composite with duplex coarse and ultrafine grain sizes and reinforced with boron carbide particulates, referred to as trimodal material. Fully reversed cyclic tests were conducted under plastic strain control at plastic strain amplitudes from 0.15 to 0.6 pct using a constant plastic strain rate in a servo-hydraulic testing system. A nonlinear elastic modulus was used to calculate the elastic contribution to the measured total strain. The LCF performance of this trimodal material is compared to previous results for unreinforced AA5083 aluminum alloy with bimodal grain size (85/15 pct CM/UM) and its coarse-grained wrought counterpart, AA5083-H131. Stress response curves for the trimodal material revealed slow hardening until failure associated with the presence of particulate reinforcements. The very small asymmetry between tension and compression stresses reflects a lack of strain localization beyond the initial cycles. The trimodal and $85 / 15$ pct $\mathrm{CM} / \mathrm{UM}$ alloys have similar and superior low cycle fatigue strength compared to AA5083-H131. From the Coffin-Manson plot, the trimodal material has a shorter fatigue life than $85 / 15$ pct CM/UM alloy and AA5083-H131 for high plastic strain amplitudes, but nearly identical life at low amplitudes. Microcracks were observed near the dominant crack on trimodal specimen surfaces at failure. Back-scattered images revealed that particulates altered the crack propagation direction; cracks nearly always propagated around particulates.

https://doi.org/10.1007/s11661-020-06129-w

(C) The Author(s) 2021

\section{INTRODUCTION}

IT is well-known that reinforcing a metal matrix with another strong and stiff material is an effective way to develop advanced materials with superior properties compared to the unreinforced counterpart, giving higher strength and stiffness, improved high-temperature properties, better wear resistance, and lower thermal expansion coefficient. ${ }^{[1,2]}$ Metal matrix composites (MMC's) offer the opportunity for lighter structures, thereby enhancing the potential for applications such as automotive, aerospace products, military, and recreational goods. ${ }^{[2-6]}$ Although MMC's have many superior

A. CONTRERAS is with the Department of Mechanical and Aerospace Engineering, University of California, One Shields Ave., Davis, CA 95616. R.G. VOGT is with the Department of Mechanical Engineering, California State University, Sacramento, $6000 \mathrm{~J}$ Street, Sacramento, CA 95819. D.M. OLIVEIRA and J.C. GIBELING are with the Department of Materials Science and Engineering, University of California, One Shields Ave., Davis, CA 95616. Contact e-mail: jcgibeling@ucdavis.edu J.M. SCHOENUNG is with the Department of Materials Science and Engineering, University of California, Irvine, CA 92697.

Manuscript submitted August 25, 2020; accepted December 11, 2020.

Article published online January 22, 2021 properties, they also commonly exhibit poor tensile ductility, lower fracture toughness, and inferior fatigue properties under some conditions compared to their base alloys. ${ }^{[5,7]}$

To produce MMC's with improved properties compared to their conventional counterparts, proper manufacturing methods are as important as material composition. By manufacturing using mechanical milling, ${ }^{[8,9]}$ properties such as strength, toughness, fatigue life, and corrosion resistance can be greatly improved compared to MMC's produced by other methods. ${ }^{[9-11]}$ Mechanical milling successfully eliminates voids between the matrix and reinforcing agent, achieving a solid-state bond through a complete mixture of the reinforcements with the matrix. ${ }^{[2]}$ Cryogenic temperature milling, or cryomilling, produces ultrafine grain structures in the matrix, resulting in improvements in strength due to grain size refinement ${ }^{[12,13]}$ and can be used to produce powders in large quantities in a relatively economical way. ${ }^{[14,15]}$

Plastic deformation during subsequent processing of MMC powders commonly causes residual stresses to remain after unloading, and these can either decrease or increase the subsequent resistance of a component to fatigue damage. Low cycle fatigue (LCF) testing is a way to understand permanent deflections, the influence 
of residual stress, the role of reinforcing particulates, and the effects of yielding during cyclic loading. ${ }^{[16]}$ For each cycle, peak tension and compression stresses are identified and changes in these quantities during the test due to material hardening or softening may be observed. The variation of the peak stresses throughout the test is important in understanding the deformation and failure mechanisms as it provides information about the mechanical stability of the microstructure and the homogeneity of deformation. In particular, asymmetry of the tension and compression peaks is evidence of strain localization. ${ }^{[17]}$ Additionally, a fatigue life plot characterizes the performance of materials, revealing critical features of crack formation and growth associated with plastic deformation and damage accumulation.

Hassan and Lewandowski recently reviewed available information regarding LCF of various particle-reinforced aluminum MMC's. ${ }^{[18]}$ Strain-life results have shown that the LCF resistance of these materials is inferior to that of the unreinforced alloys due to their lower ductility and limited ability to accommodate plastic deformation. ${ }^{[18-22]}$ A similar decrease in LCF life has been observed in alloys strengthened by grain size refinement. ${ }^{[23]}$ For example, Li et al. ${ }^{[24]}$ reported that the LCF life for coarse-grained AA5083 aluminum alloy was superior to that of ultrafine-grained alloy processed by Equal Channel Angular Pressing. In contrast, work performed by Walley et al. ${ }^{[25]}$ on unreinforced AA5083 aluminum alloy containing cryomilled (CM) and unmilled (UM) powders showed that mixing coarse and ultrafine grain sizes led to a comparable LCF life to that of the wrought AA5083 alloy, even though there was a significant increase in yield and ultimate tensile strength. This raises the important question of whether the addition of brittle ceramic particulates into this bimodal AA5083 alloy would result in an aluminum MMC with similar LCF resistance due to the beneficial effects of the coarse-grained regions.

Therefore, the purpose of this research work is to extend the previous investigation of Walley et al. ${ }^{[25]}$ and to gain a comprehensive understanding of the low cycle fatigue behavior of a novel aluminum-matrix composite containing a bimodal grain size distribution and reinforced with boron carbide $\left(\mathrm{B}_{4} \mathrm{C}\right)$ particulates, designated as trimodal material. The motivation behind the development of this material by $\mathrm{Ye}$ et al. is to expand the application of nanocomposites through high stiffness, high strength, and enhanced ductility. ${ }^{[26-29]}$ Furthermore, the coarse-grained constituent could introduce efficient toughening mechanisms for crack growth resistance, depending on its distribution and morphology. ${ }^{[30]}$ Low cycle fatigue properties of the trimodal material are analyzed and compared to previously reported data for the unreinforced alloy containing $85 \mathrm{wt}$ pct $\mathrm{CM}$ and 15 wt pct UM powders, identified as $85 / 15$ pct $\mathrm{CM} / \mathrm{UM}$ alloy (bimodal grain size distribution centered at $240 \mathrm{~nm}$ and $1.8 \mu \mathrm{m}$ ), and its coarse-grained wrought counterpart, AA5083-H131 (average grain size of $140 \mu \mathrm{m}$ ). ${ }^{[25]}$

\section{MATERIALS AND METHODS}

A detailed description of the composition, processing, and microstructure of the trimodal material has been given by Vogt, et al. ${ }^{[31]}$ Briefly, it was produced by cryomilling 80 wt pet AA5083 alloy gas-atomized powder with an average particle size less than $45 \mu \mathrm{m}$ and $20 \mathrm{wt}$ pet $\mathrm{B}_{4} \mathrm{C}$ particulates ranging from 1 to $7 \mu \mathrm{m}$ in diameter. The nanocrystalline cryomilled powder was then V-blended with equal wt pct unmilled AA5083, resulting in a composite of 10 wt pet $\mathrm{B}_{4} \mathrm{C}, 40 \mathrm{wt}$ pet cryomilled AA5083, and 50 wt pct unmilled AA5083. The resulting powder blend was then vacuum degassed, quasi-isostatically forged, and warm rolled to plate form. The microstructure of the final plate consisted of coarse-grained bands (average grain size 800 to 1000 $\mathrm{nm}$ ) without $\mathrm{B}_{4} \mathrm{C}$ particulates interwoven with ultrafine-grained regions (average grain size $181 \mathrm{~nm}$ in the longitudinal direction with a grain aspect ratio of 1.4) containing a uniform distribution of $\mathrm{B}_{4} \mathrm{C}$ particulates. ${ }^{[27,31]}$ In addition, this alloy is expected to have a fine distribution of $\mathrm{Al}_{6}(\mathrm{Mn}, \mathrm{Fe})$ particles which we anticipate have only a small influence on the fatigue behavior compared to that of the $\mathrm{B}_{4} \mathrm{C}$ particulates. ${ }^{[27]}$

Rods were cut from the trimodal plate by electro-discharge machining and were then machined to cylindrical test specimens consistent with ASTM E606 specifications. ${ }^{[2]}$ The loading axis was aligned parallel to the rolling direction of the plate. The grip sections of the specimens had a diameter of $6.35 \mathrm{~mm}$ and the gage sections had $3.175 \mathrm{~mm}$ diameters and were $10.16 \mathrm{~mm}$ in length. The gage sections were mechanically polished on a lathe rotating at a speed of $580 \mathrm{rpm}$. 400- to 2500 -grit $\mathrm{SiC}$ paper was successively used to remove machining marks and scratches. Specimens were further polished using diamond paste at 3-, 1-, and 0.25- microns successively with a nylon cloth.

LCF testing was conducted on a fully automated MTS 810 servo-hydraulic testing system incorporating hydraulic collet grips as described elsewhere. ${ }^{[25]}$ Total strain was monitored during testing using a 7.6- $\mathrm{mm}$ gage length extensometer attached to the specimens with elastic bands. All testing was done at room temperature under real-time plastic strain control using a personal computer with MTS TestStar control electronics. $^{[25,33-36]}$ Repeated tests were conducted at each plastic strain amplitude between 0.15 and 0.6 pct at a constant plastic strain rate of $10^{-3} \mathrm{~s}^{-1}$.

Controlling plastic strain during fatigue testing is useful because deformation mechanisms and damage accumulation are directly related to plastic strain, and such tests can be performed with the use of computed-variable test control ${ }^{[33]}$ in which the calculated elastic strain is subtracted from the measured total strain. In calculating plastic strain, Sommer et al. ${ }^{[37]}$ have shown that for high strength materials, the assumption of linear elastic behavior is not valid and the stress $\sigma$ can be approximated by a parabolic function of elastic strain: 


$$
\sigma=E_{\mathrm{o}} \cdot \varepsilon_{e}+k \cdot \varepsilon_{e}^{2}
$$

where $E_{\mathrm{O}}$ is the elastic modulus as elastic strain approaches zero and the constant $k$ is negative and reflects a deviation in stress from the values given by Hooke's Law. Both $E_{\mathrm{o}}$ and $k$ can be determined empirically and lead to the following relationship between true plastic strain $\varepsilon_{\mathrm{p}}$, measured load $L$, and measured total strain $e$ for a cross-sectional area, $A^{[38]}$.

$$
\begin{aligned}
\varepsilon_{\mathrm{p}} & =\varepsilon_{t}-\frac{\sqrt{E_{\mathrm{o}}^{2}+4 \cdot k \cdot \sigma}-E_{\mathrm{o}}}{2 \cdot k} \\
& =\ln (1+e)-\frac{\sqrt{E_{\mathrm{o}}^{2}+\frac{4 \cdot k \cdot L \cdot(1+e)}{A}}-E_{\mathrm{o}}}{2 \cdot k}
\end{aligned}
$$

where $\varepsilon_{t}$ is the true total strain. To find the values of $E_{\mathrm{o}}$ and $k$, a specimen was fatigue tested for a few cycles using an approximate $E_{\mathrm{o}}$ estimated from tests of the 85/ 15 pct $\mathrm{CM} / \mathrm{UM}$ material. ${ }^{[39]} E_{\mathrm{o}}$ and $k$ were fine-tuned by an iterative process of changing their values and fatigue testing for a few cycles until the hysteresis loop shape exhibited vertical loading and unloading regions and overall plastic strain symmetry. The $E_{\mathrm{o}}$ and $k$ values for trimodal material determined as outlined above are listed in Table I along with previously reported data for the other two materials. ${ }^{[25]}$

After full rupture during the LCF tests, post-failure fracture and previously polished specimen surfaces were evaluated using a FEI XL-30 FEG scanning electron microscope (SEM) operated at a beam voltage ranging from 5 to $20 \mathrm{kV}$ and a spot size ranging from 3 to 5 . Examinations were conducted using secondary electron and back-scatter electron imaging.

\section{RESULTS AND DISCUSSION}

\section{A. Hysteresis Loop Shape and Stress Response Curves}

It was previously found ${ }^{[39]}$ that the elastic modulus, $E_{\mathrm{o}}$, affects only the slope of the unloading portion of the hysteresis loop and does not affect the peak stresses. Although corrections were made to produce symmetric hysteresis loops with respect to plastic strain, it was observed that the loops were not perfectly symmetric along the strain axis. This observation is consistent with the nonlinearity and stress dependence of the elastic modulus that, according to Sommer et al., ${ }^{[37]}$ is more apparent in high strength materials. ${ }^{[40]}$ In addition, a small difference was observed between the tension and compression peak stresses, with the latter exceeding the

Table I. Nonlinear Elastic Modulus Constants

\begin{tabular}{llcc}
\hline Material & \multicolumn{1}{c}{$\Delta \varepsilon_{\mathrm{p}} / 2$} & $E_{\mathrm{o}}(\mathrm{GPa})$ & $k(\mathrm{GPa})$ \\
\hline AA5083-H131 & 0.1 to $0.7 \mathrm{pct}$ & 72.5 & -150 \\
$85 / 15$ pct $\mathrm{CM} / \mathrm{UM}^{[25]}$ & 0.1 & 73.25 & -200 \\
& 0.2 to $0.7 \mathrm{pct}$ & 72.5 & -200 \\
Trimodal & 0.15 to $0.6 \mathrm{pct}$ & 90.0 & -150 \\
\hline
\end{tabular}

former as expected from the monotonic data as a result of residual stresses. ${ }^{[31]}$ Hysteresis loops show that as the trimodal specimen cycles, it hardens at all plastic strain amplitudes as presented in Figure 1 for $\Delta \varepsilon_{\mathrm{p}} / 2=0.15$ and 0.4 pet to illustrate typical behavior. Each specimen failed suddenly due to the relatively low ductility of the trimodal material and very few tests revealed any signs of fatigue crack development in the shapes of the hysteresis loops.

The stress response curves for all tests were similar to the ones shown in Figure 2 for $\Delta \varepsilon_{\mathrm{p}} / 2=0.15$ and $0.4 \mathrm{pct}$, revealing that hardening occurred during cycling and the compression stresses were larger in magnitude than those for tension. At low plastic strain amplitudes, the trimodal material reached saturation in compression loading before failure occurred. These results are similar to the findings of Luk et al. for AA2009 reinforced with $\mathrm{SiC}^{[41]}$ and suggest that stable dislocation structures develop in the late stage of fatigue testing in the compression portion of the cycles until the specimens failed. ${ }^{[17,41,42]}$ At higher plastic strain amplitudes, the tension and compression stresses were more symmetric, and saturation did not fully develop. Instead, the trimodal specimens slowly hardened until failure. According to Hadianfard and Mai, changes in dislocation structure occur gradually under cyclic straining in such a way that the stress-strain response might take a long time to become stable in aluminum composites. If the process of crack growth begins at relatively few cycles, the MMC might not exhibit saturation, and this is more likely to happen when the LCF life is short. ${ }^{[43]}$

Most specimens failed due to cracks nucleating at a location between the extensometer knife edges. Failure is attributed to the formation and presence of microscopic cracks and their growth through the composite microstructure to form one or more macroscopic cracks. ${ }^{[44]}$ It was observed by Srivatsan et al. that for a AA2009 aluminum alloy reinforced with $\mathrm{SiC}$ particulates, ${ }^{[4]}$ the dislocation-dislocation interactions combined with an interaction of mobile dislocations with particulates resulted in hardening during fully reversed cyclic straining. Consistent with this observation, the trimodal material slowly hardened at high plastic strain amplitudes, suggesting that this response similarly occurred due to the increase in mutual interaction of dislocations and the interaction of mobile dislocations with particulates. According to Srivatsan et al., microcracks nucleate when the stress field of the dislocation pile up around the $\mathrm{SiC}$ particulates exceeds a critical value. This critical value could be the strength of the reinforcement or the cohesive strength of the matrix-reinforcement interface, causing cracking of the particulate or interfacial decohesion, respectively. ${ }^{[44]}$ Ibrahim, Mohamed, and Lavernia report the strength of $\mathrm{B}_{4} \mathrm{C}$ particulates as $2759 \mathrm{MPa}$ and the $\mathrm{Al}-\mathrm{SiC}$ bond strength as approximately $1690 \mathrm{MPa} \cdot{ }^{[4]}$ Assuming that the $\mathrm{Al}-\mathrm{B}_{4} \mathrm{C}$ interfacial strength is similar, it is likely that microcracking is caused by interfacial decohesion rather than particle cracking in the trimodal material. 


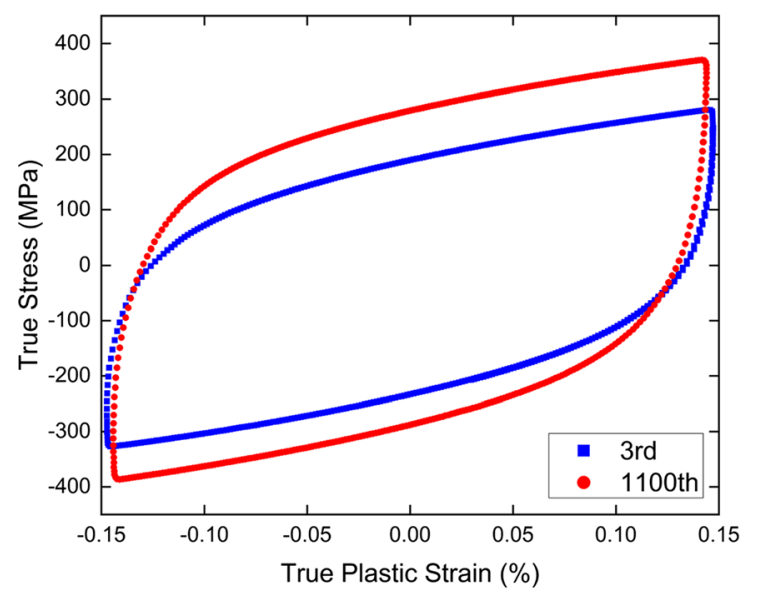

(a)

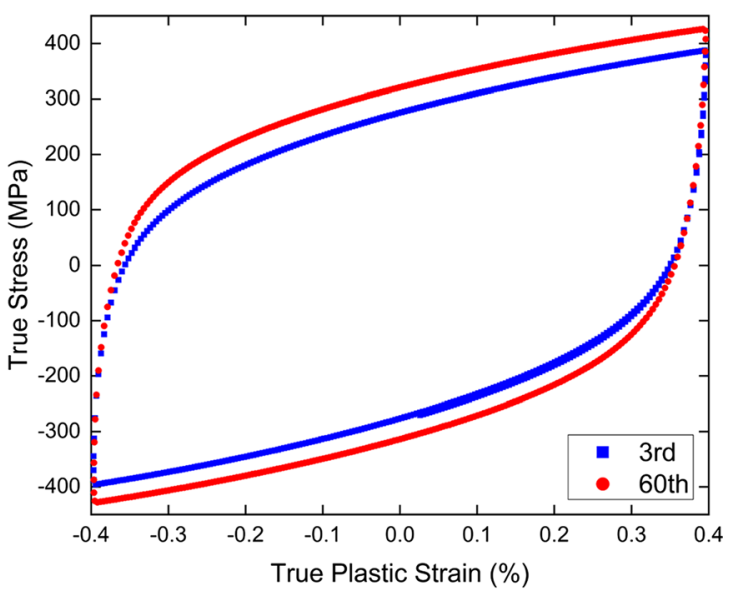

(b)

Fig. 1-Hysteresis loops for trimodal material cycled at $(a) \Delta \varepsilon_{\mathrm{p}} / 2=0.15 \mathrm{pct}$ and $(b) \Delta \varepsilon_{\mathrm{p}} / 2=0.4$ pct at the third cycle and a subsequent cycle prior to failure.

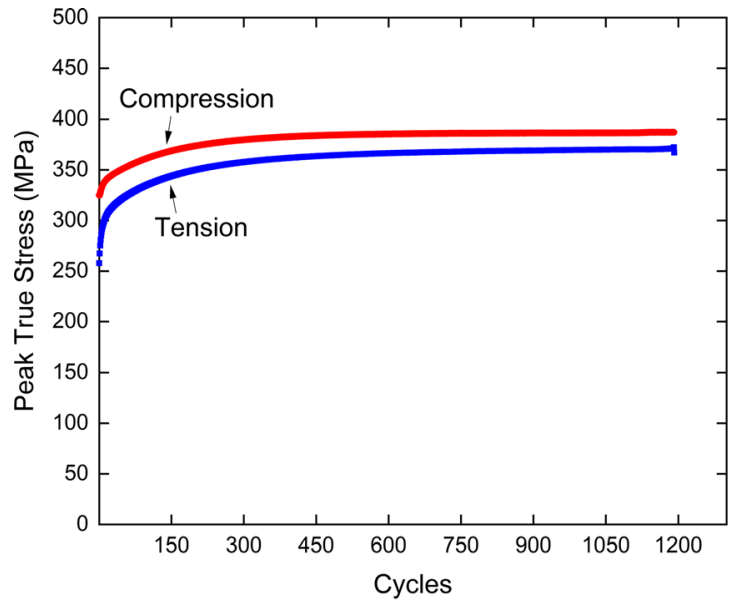

(a)

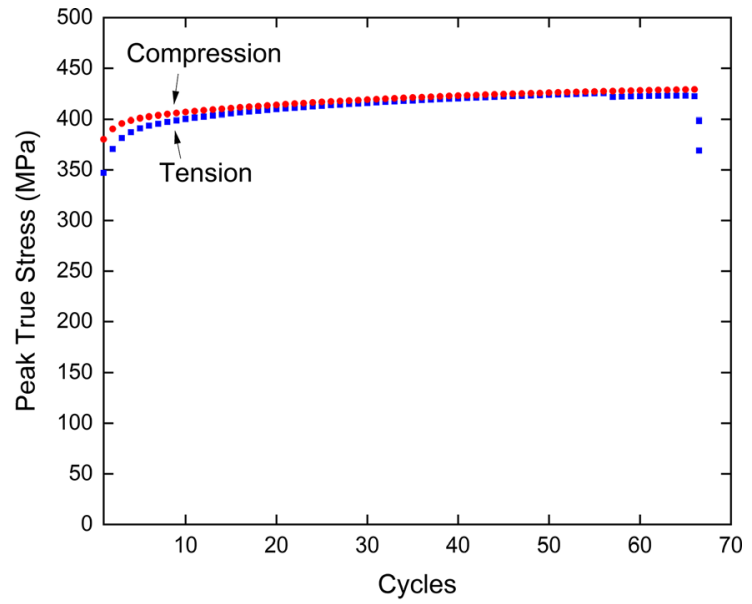

(b)

Fig. 2 - Stress response curves for trimodal material at (a) $\Delta \varepsilon_{\mathrm{p}} / 2=0.15$ pct and (b) $\Delta \varepsilon_{\mathrm{p}} / 2=0.4$ pct. The absolute values of the compression peak stresses are shown to facilitate comparison to the tension peak stresses.

\section{B. Asymmetry Factor}

To better visualize the amount of stress asymmetry, it is helpful to introduce an asymmetry factor, A, first proposed by Ma et al., ${ }^{[17]}$ as described by the following equation:

$$
A=\frac{\left(\left|\sigma_{c}\right|-\left|\sigma_{t}\right|\right)}{\left(\left|\sigma_{c}\right|+\left|\sigma_{t}\right|\right) / 2}
$$

where $\left|\sigma_{c}\right|$ and $\left|\sigma_{t}\right|$ are the magnitudes of the compression and tension peak stresses, respectively, at specific cycles. ${ }^{[38]}$ A positive asymmetry factor indicates that the magnitude of the tension stress is less than the magnitude of the compression stress and vice versa for a negative asymmetry factor. Ma et al. pointed out that asymmetry between tension and compression stresses has been observed for various materials ${ }^{[17]}$ and have attributed the asymmetry for polycrystalline copper to constraints in deformation leading to strain localization.
They also showed that the asymmetry value decreased with cycling during the stage of hardening. ${ }^{[17]}$

The asymmetry factor was calculated for the initial cycle and at half-life; these results are presented in Figure 3 over the full range of plastic strain amplitudes studied. Half-life stresses were used because most tests did not reach saturation. There is a positive asymmetry factor for the first cycle that varied with amplitude up to 0.4 pct and remained essentially constant at higher plastic strain amplitudes. This initial asymmetry is consistent with the fact that the material had been rolled prior to testing. Localization of deformation is most pronounced at low plastic strain amplitudes, and deformation becomes more homogeneous due to the activation of cross-slip and secondary slip at the high applied stresses associated with high plastic strain amplitudes. ${ }^{[4-48]}$ As a result, the amount of initial asymmetry diminished at high plastic strain amplitudes. 


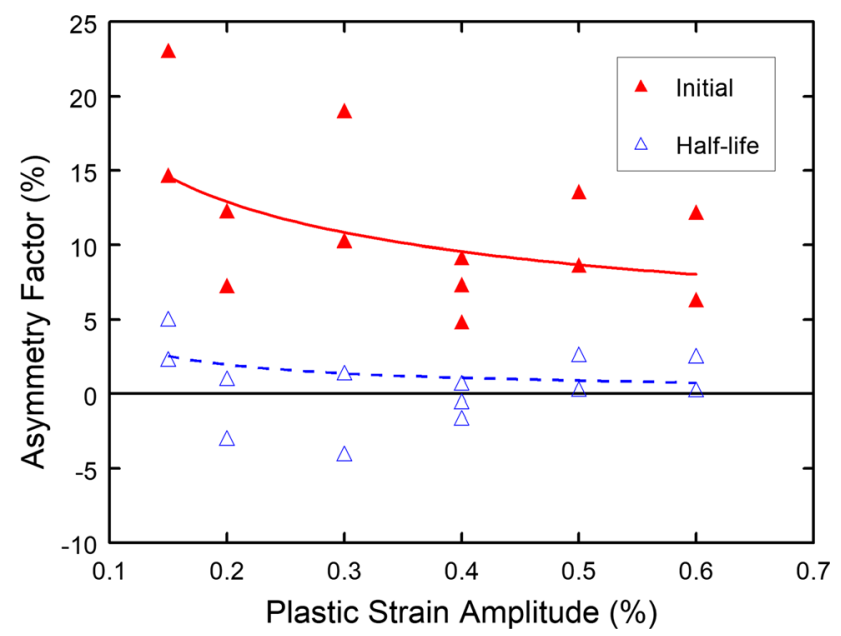

Fig. 3-Asymmetry factor as a function of plastic strain amplitude for trimodal material for the initial cycle and at half-life. The behavior of the data is represented by a power law trendline to facilitate visual comparisons of the data.

The asymmetry factor for half-life is noticeably smaller than that for the first cycle at all plastic strain amplitudes and on average is nearly zero. It also exhibits some variability with plastic strain amplitude throughout the entire range of plastic strain amplitudes. Additionally, some tests resulted in slightly negative values at amplitudes of $0.2,0.3$, and 0.4 pct. The decrease in asymmetry from first cycle to half-life is due to the material hardening and the resultant development of more homogeneous deformation, which also relieves the residual stresses initially caused by property mismatch between the different microconstituents in the trimodal material. ${ }^{[49]}$

Previous studies have reported constant asymmetry for precipitation hardened AA7075 in the T6 and T651 tempers, ${ }^{[38]}$ a dispersion strengthened Al-Mg alloy (IN-9052) and a similar alloy containing an addition of lithium (IN-905XL), ${ }^{[50]}$ and a Ni-based alloy, Inconel MA $6000 .^{[51]}$ For $85 / 15$ pet $\mathrm{CM} / \mathrm{UM}$, it was observed that the initial asymmetry factor was high for low plastic strain amplitudes and decreased at high plastic strain amplitudes, similar to the present results for trimodal material. AA5083-H131 exhibited a mostly negative asymmetry factor on the initial cycle and roughly zero asymmetry at saturation, independent of applied plastic strain amplitude. ${ }^{[39]}$ In all of these cases, the presence of asymmetry is due to the materials' distinct microstructural features that result in strain localization. ${ }^{[38]}$ From these observations, it can be deduced that only a small amount of strain localization develops during cyclic deformation of the trimodal material as reflected in the low asymmetry factor.

\section{Cyclic Stress-Strain Curves}

The cyclic stress-strain curves for the trimodal material are plotted in Figure 4 for all plastic strain amplitudes using the tension stresses at half-life along with comparable data for the bimodal grain size and conventional wrought materials. The monotonic

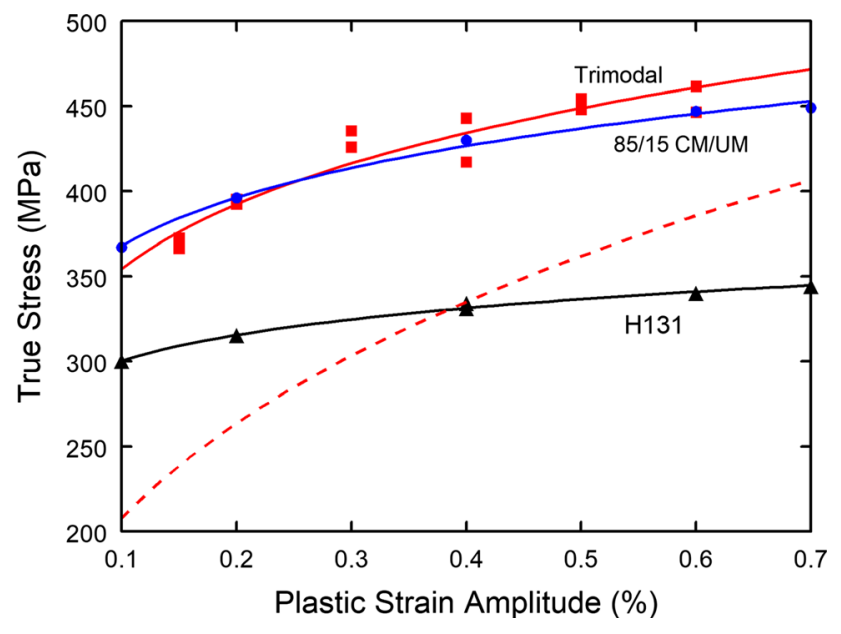

Fig. 4 - Cyclic Stress-Strain Curves (CSSC) for all three materials using stresses measured at half-life. The dashed curve represents monotonic data taken from the first cycle of trimodal material tested at 0.6 pet plastic strain amplitude.

Table II. Strain Hardening Parameters for Each Material Based on Power Law Fit

\begin{tabular}{lccc}
\hline & AA5083-H131 & $85 / 15$ pct CM/UM & Trimodal \\
\hline$k^{\prime}(\mathrm{MPa})$ & 353.5 & 470.5 & 496.8 \\
$n^{\prime}$ & 0.07 & 0.11 & 0.15 \\
$R^{2}$ & 0.994 & 0.995 & 0.905 \\
\hline
\end{tabular}

stress-strain curve for the trimodal material is represented by the tension data for the first quarter cycle of the test at 0.6 pet plastic strain amplitude. At any given plastic strain amplitude, both the bimodal and trimodal materials exhibit a higher stress than the AA5083-H131 alloy as expected from the trends in monotonic tensile strength for these materials ${ }^{[25,31]}$ and explained by the ultrafine grain size and the $\mathrm{B}_{4} \mathrm{C}$ particulates. At high plastic strain amplitudes, the trimodal material has slightly higher strength than the $85 / 15$ pct CM/UM, although the opposite is true at low amplitudes. Additionally, the cyclic data fall above the monotonic curve for all three materials, indicating cyclic hardening under fatigue loading.

The cyclic stress-strain curves can be described by Holloman power law relationship given by ${ }^{[52]}$ :

$$
\sigma=k^{\prime}\left(\frac{\Delta \varepsilon_{p}}{2}\right)^{n^{\prime}}
$$

The parameters for this equation were determined by numerically fitting the tension data points in order to find the strain hardening coefficient, $k^{\prime}$, the strain hardening exponent, $n^{\prime}$, and $R^{2}$ values describing the goodness of the fit. The resulting values for all three materials are listed in Table II.

The hardening with increasing plastic strain amplitude observed in the trimodal material is due to the presence of $\mathrm{B}_{4} \mathrm{C}$ particulate reinforcements. The 
particulates lead to the development of localized stresses in the matrix around the reinforcing particles, which intensifies work hardening of the composite matrix because of the constrained deformation in the matrix. ${ }^{[44,53-55]}$ This behavior is confirmed by the larger cyclic strain hardening exponent $n^{\prime}$ (Table II) for the trimodal composition when compared to the $85 / 15$ pct $\mathrm{CM} / \mathrm{UM}$ and the wrought AA5083-H131 materials. From this, localized stresses lead to plastic deformation near the particulates and as the stress in the matrix increases, the volume of material that is plastically deformed increases. ${ }^{[4,54,56]}$

The higher stresses under cyclic deformation when compared to monotonic behavior suggest the development of stronger microstructures under the former testing mode, which is likely due to the accumulation of dislocations at grain boundaries or in tangles or cell-like patterns in the deformed material. ${ }^{[23]}$ In fact, such dislocation configurations were observed in TEM images of wrought and cryomilled AA5083-H131 by Walley et al. ${ }^{[25]}$

\section{Fatigue Life Data}

A Coffin-Manson fatigue life plot, where life is defined as the number of reversals to failure, $2 \mathrm{~N}_{\mathrm{f}}$, was created for the three materials as shown in Figure 5. All results exhibit little scatter. It is seen that AA5083-H131 and $85 / 15$ pct CM/UM have nearly identical fatigue life for all plastic strain amplitudes. It is important to note that the stresses carried at a given plastic strain amplitude differ vastly for the two materials, with the difference ranging from 50 to $100 \mathrm{MPa}$ at low and high plastic strain amplitudes, respectively. The trimodal material data exhibit a lower slope, which indicates poorer low cycle fatigue resistance. However, it intersects the results for the other two materials at low plastic strain levels, suggesting that the trimodal composition may have superior resistance at very low plastic strain amplitudes

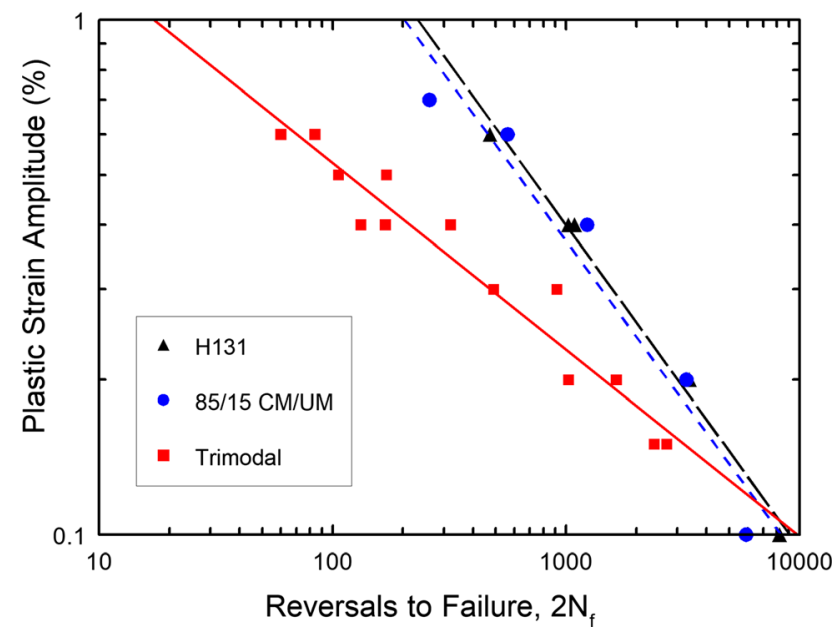

Fig. 5- Coffin-Manson plot of fatigue life data for all three material types. Solid, short-, and long-dash lines fit trimodal $\left(R^{2}=0.939\right)$, $85 / 15 \mathrm{pct} \mathrm{CM} / \mathrm{UM}\left(R^{2}=0.941\right)$, and H131 $\left(R^{2}=0.992\right)$ materials, respectively. or in the high cycle fatigue regime if the slope remains constant, most likely the result of its higher strength.

A previous study on an AA7034 reinforced with $\mathrm{SiC}^{[42]}$ showed that under total strain amplitude control, the average local plastic strain was significantly elevated in the composite microstructure compared to the unreinforced aluminum alloy matrix. The elevated local plastic strain dominates the development of fatigue damage during cyclic deformation resulting in inferior cyclic strain resistance for the reinforced metal matrix. Because the trimodal material has relatively low tensile ductility, at high plastic strain amplitudes the specimen should, and did, have a lower fatigue life compared to 85/15 pet CM/UM and AA5083-H131.

The data convergence observed in Figure 5 at low plastic strain amplitudes could be explained by the increasing contribution of strength in the fatigue performance of the trimodal material. At the low applied strains and stresses (high cycle regime), the increase in strength promoted by the addition of the particulates delays the nucleation of fatigue cracks and improves the fatigue life. ${ }^{[22]}$ In fact, Chawla and Shen observed that crack initiation takes approximately 10 pet of the total fatigue life under low cycle conditions, but cracks do not nucleate until 70-90 pct of the total life in the high cycle regime. ${ }^{[57]}$ Similar trends in fatigue performance of high strength materials at different plastic strain amplitudes were found by Han et al., ${ }^{[53]}$ Mughrabi et al. ${ }^{[58]}$, and Li et $a .^{[59]}$

\section{E. Post-Failure Examination}

Test results indicated that at all plastic strain amplitudes, the trimodal specimens failed before a 20 pct drop off in load. Figure 6 shows that the trimodal material, tested at a plastic strain amplitude of 0.2 pct, failed after only a small amount of fatigue crack growth on the fracture surface in a manner similar to $85 / 15$ pct $\mathrm{CM}$ / UM. ${ }^{[25]}$ Like the wrought alloy AA5083-H131, trimodal specimens exhibited fatigue crack fracture surfaces that

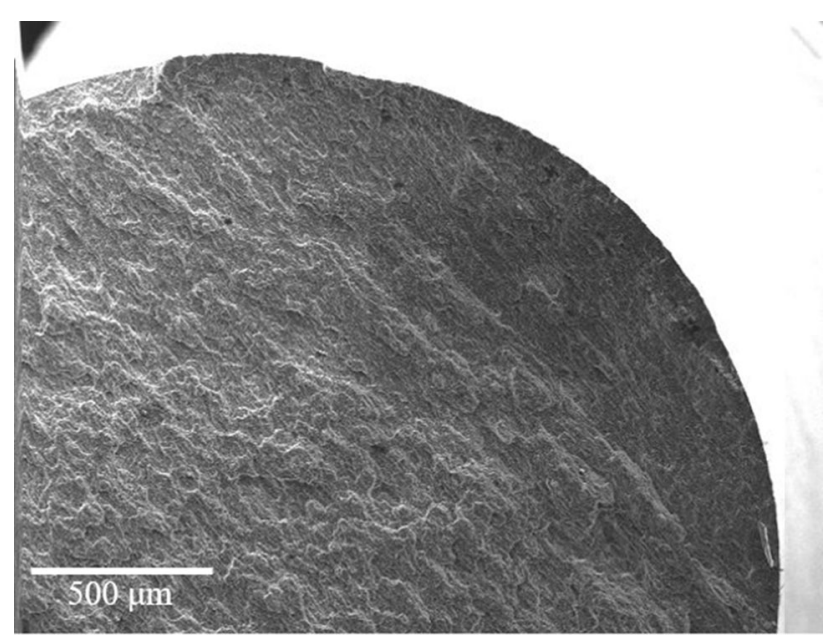

Fig. 6-Trimodal, $\Delta \varepsilon_{\mathrm{p}} / 2=0.2 \mathrm{pct}$, the flat region in the lower left is the fast fracture surface compared with fatigue fracture surface in the upper right. 
are relatively flat followed by fast fracture in the rougher region. For amplitudes below 0.4 pct, the fatigue region is readily distinguishable, but at higher plastic strain amplitudes, it is less obvious. The fracture surfaces of trimodal specimens tested at a plastic strain amplitude of 0.6 pct have no readily distinguishable fatigue region when viewed at low magnifications.

In general, fracture surfaces for trimodal material at various plastic strain amplitudes have the same overall roughness. This was also observed in previous studies, ${ }^{[53,56]}$ with 2024-Al reinforced with $\mathrm{SiC}$ and 6061-Al reinforced with $\mathrm{SiC}$ having similar fracture surfaces at various plastic strain amplitudes. Han, et al. ${ }^{[53]}$ compared the fracture surface of the composite to its unreinforced 2024-Al-matrix and found that the surfaces were significantly different, with the unreinforced material characterized by striations and the composite by dimples associated with fracture or decohesion of the $\mathrm{SiC}$ particles. The same observation was seen with the fracture surface for trimodal material and the $85 / 15$ pct $\mathrm{CM} / \mathrm{UM}^{[25]}$

A higher magnification image for a trimodal specimen tested at a plastic strain amplitude of 0.2 pct, Figure 7 , shows the fracture surface for the slow fatigue crack growth region. Again, the fatigue region exhibits a relatively flat fracture surface with no evidence of $\mathrm{B}_{4} \mathrm{C}$ particulates, indicating that cracks propagated around the particulates consistent with other studies. ${ }^{[54,56,60,61]}$ However, there is some evidence of local ductility indicated by the ridges, especially in the top center of the image. In Figure 8, a transition region is observed between the fatigue and fast fracture regions and a crack can be seen by the dark line in the middle of the image, which also represents a change in crack growth direction. Comparing the (slow) fatigue and (fast) fracture regions at low plastic strain amplitudes, it was seen that the slow fatigue region had a relatively smooth appearance but also exhibited flat ridges and fine microscopic voids reminiscent of locally ductile failure mechanisms.

Although the distinction between the slow (fatigue) and fast (fracture) crack growth regions was not apparent for most of the tests at high amplitudes, a high-magnification view in Figure 9 for a test at plastic strain

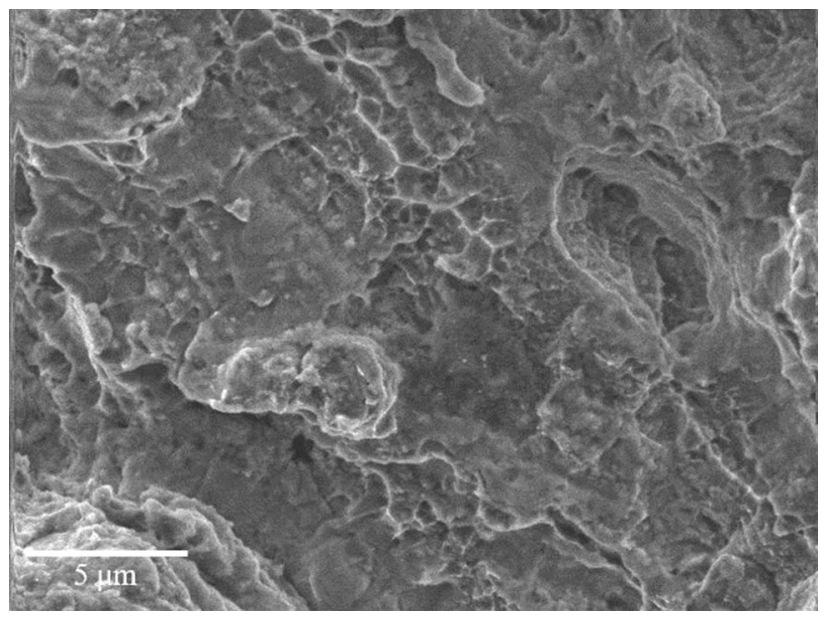

Fig. 7-Trimodal, $\Delta \varepsilon_{\mathrm{p}} / 2=0.2 \mathrm{pct}$, the fracture surface of the slow fatigue crack growth region appears relatively smooth. amplitude of 0.6 pct reveals a dense region of white ridges in the center of the image, which could represent the transition region from slow to fast fatigue. In addition, the arrow points to small striations due to crack growth in fatigue. Overall, the fracture surface observations for the trimodal are different from those for $85 / 15$ pct $\mathrm{CM} /$ $\mathrm{UM}$ for the fast fatigue region in that the $85 / 15$ pct $\mathrm{CM} /$ UM did not exhibit features representing local ductility such as those seen in the trimodal material, although it did have greater macroscopic ductility. ${ }^{[25]}$

Polished surfaces of the gage sections were observed for tests at both $\Delta \varepsilon_{p} / 2=0.3$ pct and $\Delta \varepsilon_{p} / 2=0.6$ pct using the back-scatter electron detector. Boron carbide can be identified as the dark spots in the back-scatter electron images. In Figure $10\left(\Delta \varepsilon_{p} / 2=0.3 \mathrm{pct}\right)$, it is seen that a crack grew perpendicular to the loading axis in a coarse-grained region bordering a high concentration of $\mathrm{B}_{4} \mathrm{C}$ in the finer grains, and it does not enter the $\mathrm{B}_{4} \mathrm{C}$-rich region as it grows. Figure 10 also shows microcracks in the coarse-grained region, near the

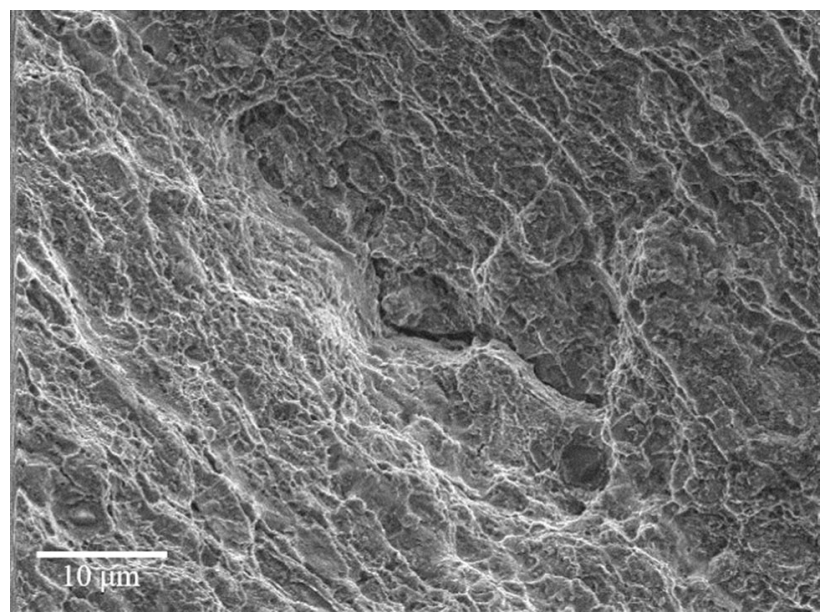

Fig. 8-Trimodal, $\Delta \varepsilon_{\mathrm{p}} / 2=0.2 \mathrm{pct}$, the transition region of slow fatigue and fast fracture is shown along with a crack developed between the two regions.

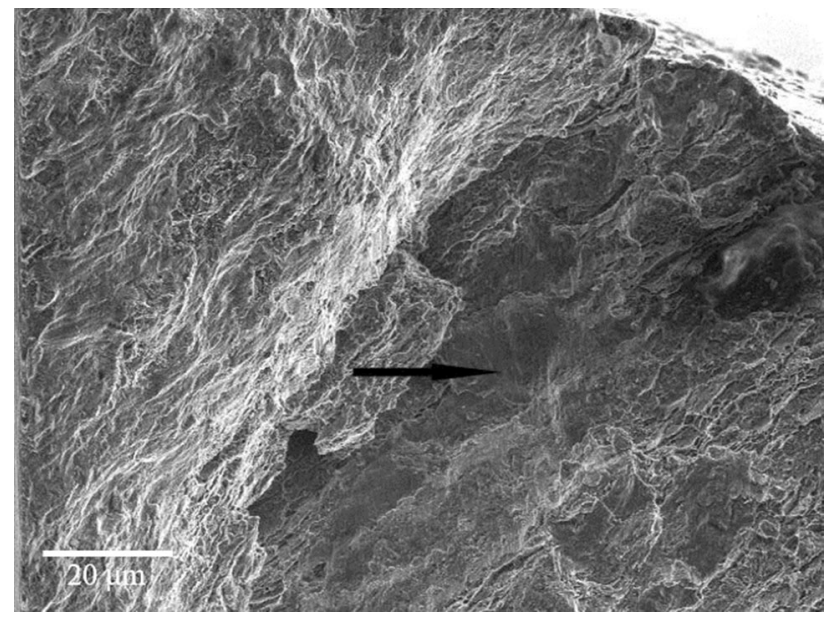

Fig. 9-Trimodal, $\Delta \varepsilon_{\mathrm{p}} / 2=0.6$ pct, black arrow points to striations, which are an indication of slow fatigue crack growth. 


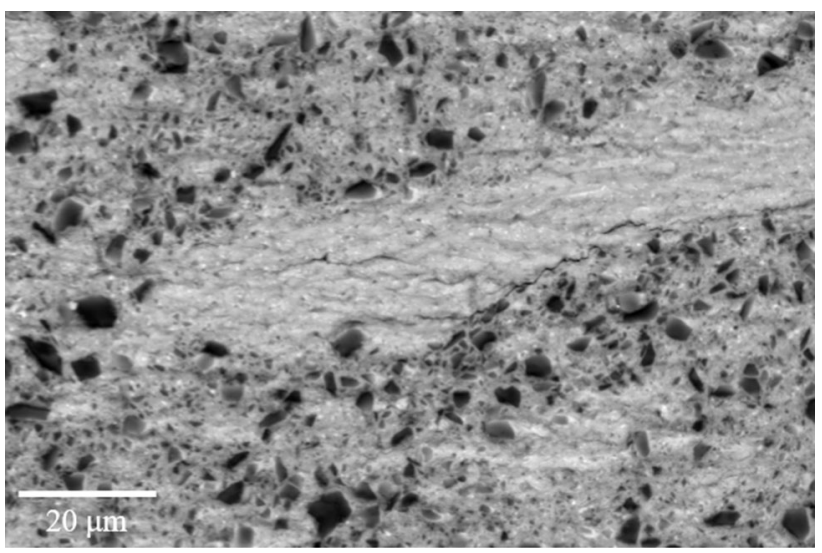

Fig. 10 -Trimodal, $\Delta \varepsilon_{\mathrm{p}} / 2=0.3 \mathrm{pct}$, crack growing around high concentration of boron carbide.

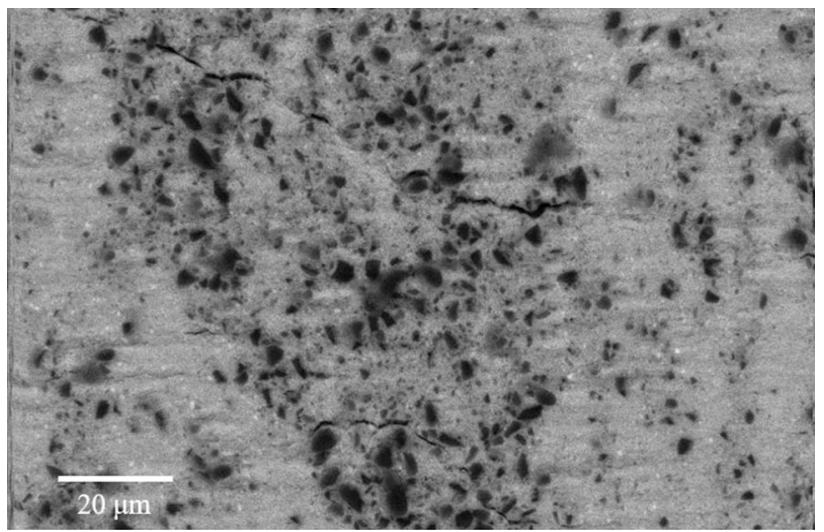

Fig. 11-Trimodal, $\Delta \varepsilon_{\mathrm{p}} / 2=0.6 \mathrm{pct}$, microcracks traveling around boron carbide. Upper left region shows crack being bridged by a particulate.

dominant crack, suggesting that crack growth occurs by linking of microcracks. Similar results were observed during cyclic straining of AA5083-H131 and 85/15 pct $\mathrm{CM} / \mathrm{UM} \cdot{ }^{[25]}$ In Figure 11, it is seen that as cracks grow at $\Delta \varepsilon_{p} / 2=0.6 \mathrm{pct}$, they generally travel around the boron carbide particulates, as suggested by the observations of the fracture surfaces. However, in the upper left region, there is evidence that some cracks are bridged by the particulates.

Trimodal specimens tested to half-life were examined and showed that little fatigue damage was evident on the specimen's gage section. In contrast, AA5083-H131 and $85 / 15$ pct $\mathrm{CM} / \mathrm{UM}$ developed many microcracks ranging from 20 to 50 microns in size when tested to half-life. This difference could be attributed to the limited number of cycles applied due to the trimodal material having low ductility and more localized damage accumulation.

\section{CONCLUSIONS}

In this study, the low cycle fatigue behavior of a cryomilled AA5083 Al-matrix alloy with bimodal grain size and reinforced with $\mathrm{B}_{4} \mathrm{C}$ particles (trimodal material) was investigated. The results for this material were compared to unreinforced cryomilled AA5083 aluminum alloy with bimodal grain size $(85 / 15$ pct $\mathrm{CM} /$ UM) and its coarse-grained counterpart, AA5083-H131. Specific observations include the following:

1. The stress response curves for the trimodal material exhibited slow hardening until failure. At low plastic strain amplitudes, saturation developed in compression loading, suggesting that stable dislocation structures develop in the late stages of fatigue testing. At higher plastic strain amplitudes, saturation did not fully develop. The stress response results are consistent with the occurrence of hardening due to the increase in mutual interaction of dislocations and the interaction of mobile dislocations with particulates.

2. The asymmetry between tension and compression stresses in the trimodal composite was high during the initial cycle at low plastic strain amplitudes, but reached a plateau at lower levels at high plastic strain amplitudes. Thus, deformation is localized at low plastic strain amplitudes but more homogeneous due to the activation of cross-slip and secondary slip at the higher applied stresses associated with high plastic strain amplitudes. The asymmetry factor at half-life was lower than its initial value and is nearly zero for all plastic strain amplitudes. This was due to the material hardening and a consequent reduction in strain localization within the specimen.

3. The cyclic stress-strain curves show that trimodal material and $85 / 15$ pct $\mathrm{CM} / \mathrm{UM}$ have similar half-life stresses that are superior compared to AA5083-H131. The higher hardening rate in the trimodal material compared to the $85 / 15$ pct $\mathrm{CM} /$ UM material is due to the localized stress in the matrix near particulate reinforcements.

4. Trimodal material has a much lower fatigue life than 85/15 pct CM/UM and AA5083-H131 at high plastic strain amplitudes, but appears to have similar fatigue life for low plastic strain amplitudes. The difference in fatigue life is attributed to the high local damage in the composite microstructure compared to the unreinforced aluminum alloy metal matrix.

5. SEM images reveal that fast fracture regions in the trimodal material are similar at all plastic strain amplitudes with evidence of local ductility throughout the surface. Particulates were not visible indicating that cracks propagated around the particulates. In addition, microcracks were observed on polished specimen surfaces near the dominant crack. Back-scattered images showed that particulates altered crack propagation direction; cracks nearly always propagated around particulates.

6. Trimodal material, a cryomilled Al-matrix composite reinforced with $\mathrm{B}_{4} \mathrm{C}$ particulates and blended with unmilled powders, has higher strength but inferior low cycle fatigue properties when compared to $85 / 15$ pct $\mathrm{CM} / \mathrm{UM}$ (unreinforced matrix) and AA5083-H131 (base alloy). The stresses at half-life are superior to AA5083-H131 and similar to 85/15 pct $\mathrm{CM} / \mathrm{UM}$. In applications where low cycle 
fatigue resistance is a critical design concern, 85/15 pct $\mathrm{CM} / \mathrm{UM}$ would be preferred over trimodal material because of its better fatigue life. However, trimodal material could still be a suitable candidate for applications that require high stiffness and high strength, or under high cycle fatigue conditions.

\section{ACKNOWLEDGMENTS}

We would like to thank the University of California, Davis, and the Samueli School of Engineering at the University of California, Irvine for financial support. We would also like to thank Jennifer (Walley) Carter for fruitful discussions during this research project.

\section{OPEN ACCESS}

This article is licensed under a Creative Commons Attribution 4.0 International License, which permits use, sharing, adaptation, distribution and reproduction in any medium or format, as long as you give appropriate credit to the original author(s) and the source, provide a link to the Creative Commons licence, and indicate if changes were made. The images or other third party material in this article are included in the article's Creative Commons licence, unless indicated otherwise in a credit line to the material. If material is not included in the article's Creative Commons licence and your intended use is not permitted by statutory regulation or exceeds the permitted use, you will need to obtain permission directly from the copyright holder. To view a copy of this licence, visit http://creat ivecommons.org/licenses/by/4.0/.

\section{REFERENCES}

1. D.J. Lloyd: Int. Mater. Rev., 1994, vol. 39, pp. 1-23.

2. J.C. Ye, J.H. He, and J.M. Schoenung: Metall. Mater. Trans. A, 2006, vol. 37A, pp. 3099-3109.

3. M.J. Koczak, S.C. Khatri, J.E. Allison, and M.G. Bader: in Fundamentals of Metal Matrix Composites, S. Suresh, A. Mortensen, and A. Needleman, eds., Butterworth-Heinemann, Stoneham, 1993, pp. 297-326.

4. T.S. Srivatsan, T.S. Sudarshan, and E.J. Lavernia: Prog. Mater. Sci., 1995, vol. 39, pp. 317-409.

5. S.V. Nair, J.K. Tien, and R.C. Bates: Int. Met. Rev., 1985, vol. 30, pp. 275-90.

6. J.J. Lewandowski: in: Comprehensive Composite Materials, Carl Zweben, ed., Pergamon, Oxford, 2000, pp. 151-87.

7. D.F. Hasson, S.M. Hoover, and C.R. Crowe: J. Mater. Sci., 1985, vol. 20, pp. 4147-54.

8. M.S. Zedalis, P.S. Gilman and S.K. Das. in High Performance Composites for the 1990s, S. K. Das, C. P. Ballard and F. Marikar, eds., The Minerals, Metals and Materials Society, Warrendale, 1991, pp. 61-82.

9. J.H. Weber and R.D. Schelling: in Dispersion Strengthened Aluminum Alloys, Y-W. Kim and W.M. Griffith, eds., The Minerals, Metals and Materials Society, Warrendale, PA, 1988, pp 467-82.

10. C. Suryanarayana: Prog. Mater. Sci., 2001, vol. 46, pp. 1-184.

11. V.L. Tellkamp, A. Melmed, and E.J. Lavernia: Metall. Mater. Trans. A, 2001, vol. 32A, pp. 2335-43.
12. C. Goujon, P. Goeuriot, M. Chedru, J. Vicens, J.L. Chermant, F. Bernard, J.C. Niepce, P. Verdier, and Y. Laurent: Powder Technol., 1999, vol. 105, pp. 328-36.

13. J.H. He and J.M. Schoenung: Metall. Mater. Trans. A, 2003, vol. 34A, pp. 673-83.

14. D.G. Morris: Mechanical Behaviour of Nanostructured Materials, Trans Tech Publications, Zuerich, 1998.

15. J.C. Ye and J.M. Schoenung: Adv. Eng. Mater., 2004, vol. 6, pp. 656-64.

16. N.E. Dowling: Mechanical Behavior of Materials: Engineering Methods for Deformation, Fracture and Fatigue, 3rd ed., Pearson Prentive Hall, Upper Saddle River, 2007, pp. 649-705.

17. B.T. Ma, Z.G. Wang, A.L. Radin, and C. Laird: Mater. Sci. Eng. A, 1990, vol. 129, pp. 197-206.

18. H.A. Hassan and J.J. Lewandowski: in Comprehensive Composite Materials II, P.W.R. Beaumont and C.H., ed., Zweben, Elsevier, 2018, pp. 86-136.

19. S.K. Koh, S.J. Oh, C. Li, and F. Ellyin: Int. J. Fatigue, 1999, vol. 21, pp. 1019-32.

20. J.J. Bonnen, J.E. Allison, and J.W. Jones: Metall. Trans. A, 1991, vol. 22, pp. 1007-19.

21. N.L. Han, Z.G. Wang, and L.Z. Sun: Scr. Metall. Mater., 1995, vol. 33, pp. 781-87.

22. J. Xia, J.J. Lewandowski, and M.A. Willard: Mater. Sci. Eng. A, 2020, vol. 770, pp. 1-10.

23. H. Mughrabi and H.W. Hoppel: Int. J. Fatigue, 2010, vol. 32, pp. 1413-27.

24. M. Li, A. Goyal, V. Doquet, N. Ranc, and J.P. Couzinie: Int. J. Fatigue, 2019, vol. 121, pp. 84-97.

25. J.L. Walley, E.J. Lavernia, and J.C. Gibeling: Metall. Mater. Trans. A, 2009, vol. 40A, pp. 2622-30.

26. L. Jiang, K.K. Ma, H. Yang, M.J. Li, E.J. Lavernia, and J.M. Schoenung: JOM, 2014, vol. 66, pp. 898-908.

27. Y. Li, Y.H. Zhao, V. Ortalan, W. Liu, Z.H. Zhang, R.G. Vogt, N.D. Browning, E.J. Lavernia, and J.M. Schoenung: Mater. Sci. Eng. A, 2009, vol. 527, pp. 305-16.

28. J. Ye, B.Q. Han, Z. Lee, B. Ahn, S.R. Nutt, and J.M. Schoenung: Scr. Mater., 2005, vol. 53, pp. 481-86.

29. D. Witkin, Z. Lee, R. Rodriguez, S. Nutt, and E. Lavernia: Scr. Mater., 2003, vol. 49, pp. 297-302.

30. Y. Zhang, T.D. Topping, H. Yang, E.J. Lavernia, J.M. Schoenung, and S.R. Nutt: Metall. Mater. Trans. A, 2015, vol. 46A, pp. 1196-204.

31. R.G. Vogt, Z. Zhang, T.D. Topping, E.J. Lavernia, and J.M. Schoenung: J. Mater. Process. Technol., 2009, vol. 209, pp. $5046-53$.

32. ASTM International: E606-04: Standard Test Method for Strain-Controlled Fatigue Testing, ASTM International, West Conshohocken, 2004.

33. S.L. Dickerson and J.C. Gibeling: Mater. Sci. Eng. A, 2000, vol. 278, pp. 121-34.

34. G.C. Kaschner and J.C. Gibeling: Mater. Sci. Eng. A, 2002, vol. 336 , pp. $170-76$.

35. G.C. Kaschner and J.C. Gibeling: Scr. Mater., 1996, vol. 35, pp. 1397-1402.

36. G.C. Kaschner and J.C. Gibeling: Acta Mater., 2002, vol. 50, pp. 653-62.

37. C. Sommer, H.J. Christ, and H. Mughrabi: Acta Metall. Mater., 1991, vol. 39, pp. 1177-87.

38. J.M. Meininger, S.L. Dickerson, and J.C. Gibeling: Fatigue Fract. Eng. Mater. Struct., 1996, vol. 19, pp. 85-97.

39. J.L. Walley: Low Cycle Fatigue of Ultra-fine Grained Aluminum Alloy 5083. Master of Science. University of California, Davis, Davis, CA, 2008.

40. M. Matsuzuki and S. Horibe: Mater. Sci. Eng. A, 2009, vol. 504, pp. 169-74.

41. M.J. Luk, F.A. Mirza, D.L. Chen, D.R. Ni, B.L. Xiao, and Z.Y. Ma: Mater. Des., 2015, vol. 66, pp. 274-83.

42. T.S. Srivatsan, M. Al-Hajri, W. Hannon, and V.K. Vasudevan: Mater. Sci. Eng. A, 2004, vol. 379, pp. 181-96.

43. M.J. Hadianfard and Y.W. Mai: J. Mater. Sci., 2000, vol. 35, pp. 1715-23.

44. T.S. Srivatsan, M. Al-Hajri, and V.K. Vasudevan: Int. J. Fatigue, 2005, vol. 27, pp. 357-71. 
45. I.A. Ibrahim, F.A. Mohamed, and E.J. Lavernia: J. Mater. Sci., 1991, vol. 26, pp. 1137-56.

46. T.H. Sanders and E.A. Starke: Metall. Trans. A, 1976, vol. 7, pp. $1407-18$.

47. T.H. Sanders, D.A. Mauney and J.T. Staley: in Fundamental Aspects of Structural Alloy Design, R.I., Wilcox Jaffee, B.A., eds., Plenum Press, New York, NY, 1977, pp. 487-519.

48. P. Li, N.J. Marchand, and B. Ilschner: Mater. Sci. Eng. A, 1989, vol. 119 , pp. $41-50$.

49. J. Long, Q. Pan, N. Tao, and L. Lu: Mater. Res. Lett., 2018, vol. 6, pp. 456-61.

50. M.E. Mercer, S.L. Dickerson, and J.C. Gibeling: Mater. Sci. Eng. A, 1995, vol. 203, pp. 46-58.

51. J. Bressers and E. Arzt, In High Temperature Alloys for Gas Turbines and Other Applications, W. Betz, R. Brunetaud, D. Coutsouradis, H. Fischmeister, T.B. Gibbons, I. Kvernes, Y. Lindblom, J.B. Marriott and D.B. Meadowcroft, eds., D. Riedel Publishing Company, Dordrecht, Netherlands, 1986, pp 1067-88.

52. J.H. Hollomon: T. Am. I Min. Met. Eng., 1945, vol. 162, pp. 268-90.
53. N.L. Han, Z.G. Wang, W.L. Wang, G.D. Zhang, and C.X. Shi: Compos. Sci. Technol., 1999, vol. 59, pp. 147-55.

54. T.S. Srivatsan: Int. J. Fatigue, 1995, vol. 17, pp. 183-99.

55. R. Thimmarayan and G. Thanigaiyarasu: Int. J. Adv. Manuf. Technol., 2010, vol. 48, pp. 625-32.

56. T.S. Srivatsan, M. Al-Hajri, B. Hotton, and P.C. Lam: Appl. Compos. Mater., 2002, vol. 9, pp. 131-53.

57. N. Chawla and Y.L. Shen: Adv. Eng. Mater., 2001, vol. 3, pp. $357-70$.

58. H. Mughrabi, H.W. Hoppel, and M. Kautz: Scr. Mater., 2004, vol. 51, pp. 807-12.

59. W. Li, Z.H. Chen, D. Chen, J. Teng, and C.H. Li: J. Mater. Sci., 2011, vol. 46, pp. 1153-60.

60. L. Ceschini, G. Minak, and A. Morri: Compos. Sci. Technol., 2006, vol. 66, pp. 333-42.

61. C. Kaynak and S. Boylu: Mater. Des., 2006, vol. 27, pp. 776-82.

Publisher's Note Springer Nature remains neutral with regard to jurisdictional claims in published maps and institutional affiliations. 